\title{
Correction to: Toxicity of Copper Oxide (CuO) Nanoparticles on Human Blood Lymphocytes
}

\author{
Evelyn Assadian ${ }^{1,2} \cdot$ Mohammad Hadi Zarei $^{2} \cdot$ Ali Ghanadzadeh Gilani ${ }^{1} \cdot$ Mehrzad Farshin $^{2} \cdot$ Hamid Dezhampanah $^{1}$. \\ Jalal Pourahmad ${ }^{2}$
}

Published online: 20 February 2019

(C) Springer Science+Business Media, LLC, part of Springer Nature 2019

\section{Correction to: Biological Trace Element Research}

https://doi.org/10.1007/s12011-017-1170-4

The original version of this article unfortunately contained mistakes. The name Hamid Degampanah is corrected to "Hamid Dezhampanah". Affiliation 1 is corrected to University of Guilan from Guilan University.

Publisher's Note Springer Nature remains neutral with regard to jurisdictional claims in published maps and institutional affiliations.

The online version of the original article can be found at https://doi.org/ 10.1007/s12011-017-1170-4

\footnotetext{
Hamid Dezhampanah h.dpanah@guilan.ac.ir

$\bowtie$ Jalal Pourahmad

j.pourahmadjaktaji@utoronto.ca

1 Department of Chemistry, Faculty of Science, University of Guilan, Guilan, P. O. Box: 41335-1914, Rasht, Iran
}

2 Department of Pharmacology and Toxicology, Faculty of Pharmacy, Shahid Beheshti University of Medical Sciences,

P.O. Box 14155-6153, Tehran, Iran 